\title{
1 Evolution of a cis-acting SNP that controls Type VI Secretion in Vibrio cholerae
}

2 Siu Lung $\mathrm{Ng}^{1,3,4}$, Sophia Kammann ${ }^{1,3,4}$, Gabi Steinbach ${ }^{2,4}$, Tobias Hoffmann ${ }^{1,3}$, Peter J

3 Yunker ${ }^{2,4}$, Brian K. Hammer ${ }^{1,3,4 \#}$

$4 \quad{ }^{1}$ School of Biological Sciences, Georgia Institute of Technology, Atlanta, Georgia, USA

$5{ }^{2}$ School of Physics, Georgia Institute of Technology, Atlanta, Georgia, USA

$6 \quad{ }^{3}$ Parker H. Petit Institute for Bioengineering \& Bioscience, Georgia Institute of Technology,

7 Atlanta, Georgia, USA

$8{ }^{4}$ Center for Microbial Diseases and Infection, Georgia Institute of Technology, Atlanta,

9 Georgia, USA

11 \#Corresponding author: brian.hammer@biology.gatech.edu

13 Running title: Evolution of the $V$. cholerae T6SS by a cis-acting SNP 


\section{Abstract}

Mutations in regulatory mechanisms that control gene expression contribute to phenotypic

diversity and thus facilitate the adaptation of microbes and other organisms to new niches.

17 Comparative genomics can be used to infer rewiring of regulatory architecture based on large

effect mutations like loss or acquisition of transcription factors but may be insufficient to identify small changes in non-coding, intergenic DNA sequence of regulatory elements that drive phenotypic divergence. In human-derived Vibrio cholerae, the response to distinct chemical cues triggers production of multiple transcription factors that can regulate the Type VI Secretion System (T6), a broadly distributed weapon for interbacterial competition. However, to date, the signaling network remains poorly understood because no regulatory element has been identified for the major T6 locus. Here we identify a conserved cis-acting single nucleotide polymorphism (SNP) controlling T6 transcription and activity. Sequence alignment of the T6 regulatory region from diverse $V$. cholerae strains revealed conservation of the SNP that we rewired to interconvert $V$. cholerae T6 activity between chitin-inducible and constitutive states. This study supports a model of pathogen evolution through a noncoding cis-regulatory mutation and preexisting, active transcription factors that confers a strains adapted to environmental niches. 
34 Organisms sense external cues with regulatory circuits that trigger the production of

35 transcription factors, which bind specific DNA sequences at promoters ("cis" regulatory

elements) to activate target genes. Mutations of transcription factors or their regulatory

elements create phenotypic diversity, allowing exploitation of new niches. Waterborne

pathogen Vibrio cholerae encodes the Type VI Secretion System "nanoweapon" to kill

competitor cells when activated. Despite identification of several transcription factors, no regulatory element has been identified in the promoter of the major Type VI locus, to date.

41 Combining phenotypic, genetic, and genomic analysis of diverse $V$. cholerae strains, we discovered a single nucleotide polymorphism in the Type VI promoter that switches its killing activity between a constitutive state beneficial outside hosts and an inducible state for constraint in a host. Our results support a role for non-coding DNA in adaptation of this pathogen.

\section{Introduction}

48 A central role in the dynamic, temporal control of gene expression is played by transcription

49 factors (TFs), diffusible "trans" products that bind to molecular switches within DNA sequences termed "cis"-regulatory elements (CREs). In eukaryotes, which lack horizontal gene transfer (HGT), mutations in CREs that alter TF binding sites are major contributors to 
52 phenotypic diversity (1-3). In bacteria, pervasive HGT of TFs can alter entire regulatory circuits

53 that allow adaptation to new niches, as prominently demonstrated in Vibrio fischeri, where

54 host range is altered by the presence or absence of RcsS, a TF of biofilm and colonization genes

$55 \quad(4,5)$. By contrast, specific mutations at CREs in non-coding DNA are more difficult to identify

56 and receive less attention as drivers of phenotypic divergence and evolutionary adaptation

57 (6). Thus, elucidation of how microbes adapt to new niches, a process of fundamental importance in bacterial pathogenesis, requires coupling of genome-wide computational methods with experimental approaches to map the cis- and trans-regulatory interactions across and within species.

61

To understand how mutations play a role in microbial adaptation, pathogenic viruses and bacteria with lifestyles that exploit niches within and outside a human host are of great interest. Following ingestion, pandemic strains of the bacterium Vibrio cholerae can colonize the human gastrointestinal tract and secrete the cholera toxin that leads to the often fatal diarrhea responsible for seven pandemics to date ( $\underline{7-9})$. Conversely, $V$. cholerae isolated from

67 non-human niches lack the horizontally-acquired prophage that carries the cholera toxin, and cause mild illness (10). By contrast, all sequenced $V$. cholerae encode a Type VI Secretion System (T6), a broadly distributed "nano-harpoon" weapon that injects toxic effector proteins 
71 its broad distribution among bacteria including those of the human gut, there is intense interest in understanding the T6 interactions between our microbiota and foreign pathogens, and whether they can be manipulated to influence health (13).

V. cholerae obtained from humans carry a limited arsenal of effectors and a T6 believed to be

tailored for in vivo success $(\underline{11}, \underline{14-19})$, while strains from non-human niches encode a more

diverse effector repertoire $(\underline{11}, \underline{14}, \underline{20}, \underline{21})$. To date, however, adaptative evolution

mechanisms of T6 regulation in $V$. cholerae derived from non-human sources have largely 
90 To understand the regulatory differences in $V$. cholerae strains, we examine here several

91 environmental isolates that exhibit T6-mediated killing (31). Despite encoding functional

92 signaling circuity and TFs, we find that QstR is dispensable for killing and that TfoY plays only

93 a minor role in the strains tested. Thus, existing regulatory models fail to explain the T6 control

94 in $V$. cholerae from human and non-human sources. Genomic analysis identifies one conserved non-coding single-nucleotide polymorphism (SNP) that we show interconverts $V$.

cholerae T6 activity between chitin-inducible and constitutive states, which are QstRthe human host.

\section{Results and Discussion}

102 Constitutive, in vitro T6 activity requires neither QstR nor TfoY.

103 In pandemic C6706, high cell density conditions (HCD) and chitin are required for induction of

$104 q s t R$ which leads to activation of T6 genes. In the absence of chitin, C6706 with qstR expressed

105 from a heterologous promoter (defined here as qst $R^{*}$ ) reduces survival of Escherichia coli

106 "target" cells in co-culture by over 4-orders of magnitude $(\sim 10,000)$, compared to wildtype

107 (WT) C6706, a T6 strain with a mutation in an essential structural gene ( $\Delta$ vas $K$ ), and a strain 
bioRxiv preprint doi: https://doi.org/10.1101/2022.01.11.475911; this version posted February $14,2022$. The copyright holder for this

preprint (which was not certified by peer review) is the author/funder, who has granted bioRxiv a license to display the preprint in perpetuity. It is made available under aCC-BY-NC-ND 4.0 International license.

$109 \mathrm{T6}^{+}$qstR* strain, but eliminates the robust killing in the non-pandemic strain V52 (serogroup

110 O37), which requires TfoY but not QstR (Fig. 1B) (26).

111

112 To determine whether QstR or TfoY participates in control of the T6 in non-human strains, we

113 examined 3223-74, a genetically-amenable, T6-proficient environmental strain (31). Like V52,

114 3223-74 does not require QstR to efficiently kill E. coli in conditions without chitin, but

115 surprisingly, also does not require TfoY. Isogenic strains carrying the $\Delta t f o Y$ and $\Delta q s t R \Delta t f o Y$

116 mutations retain $>99.99 \%$ killing activity, with only modest $E$. coli survival (Fig. $1 C$ ). Gene

117 fusions of the $5^{\prime}$ intergenic region (IGR) of the major T6 cluster of each strain fused to green

118 fluorescent protein $(g f p)$ confirm that transcriptional differences account for the killing

119 observed, with maximal $g f p$ expression mirroring activity (i.e. low $E$. coli survival with high gfp

120 expression, and vice versa) (Fig. 1D-F). Confocal microscopy reinforces the negligible role of

121 TfoY on killing by 3223-74, with a $\Delta$ tfoY mutation having little effect on killing WT (Fig. 1G).

122 Transcription of plasmid-borne reporters is significantly higher in $V$. cholerae than in $E$. coli

123 (Fig. S1), supporting a hypothesis that an additional $V$. cholerae-specific regulator of the T6

124 may remain to be identified (Fig. S1). 

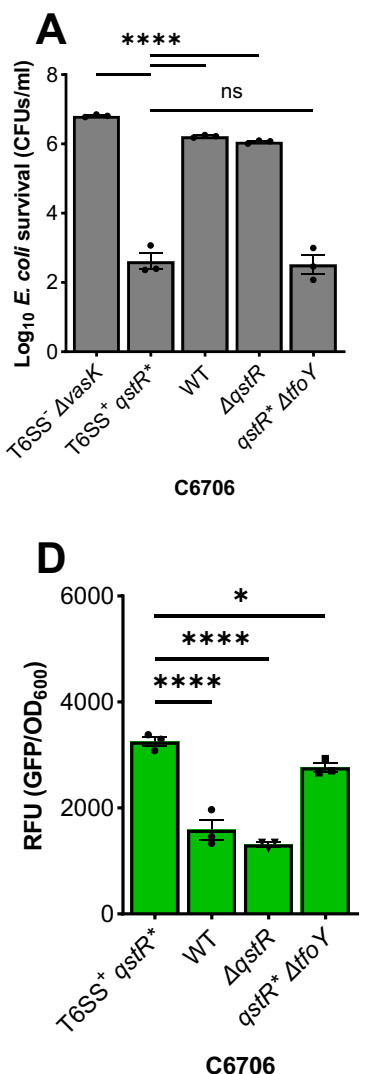

G

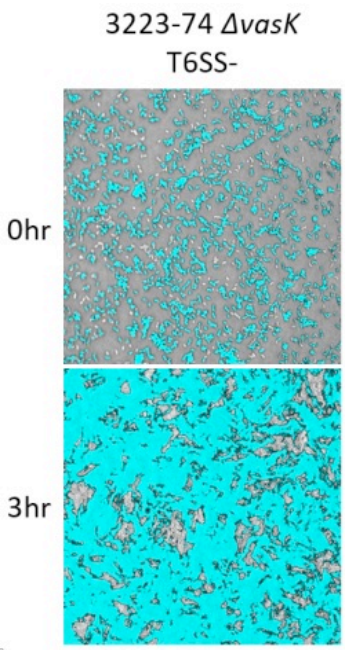

B

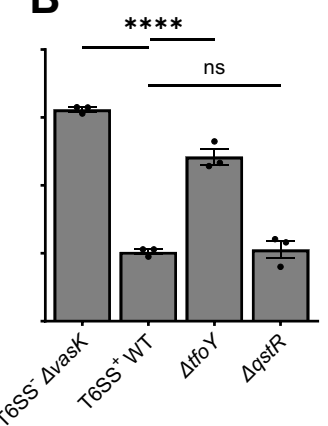

V52

E

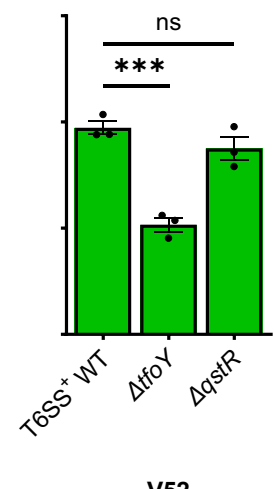

V52
C

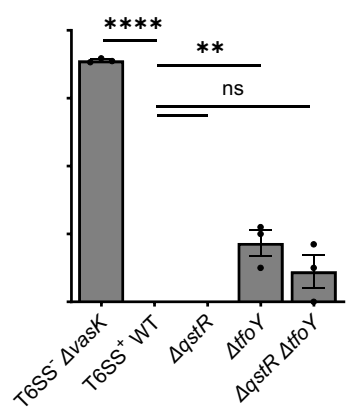

3223-74

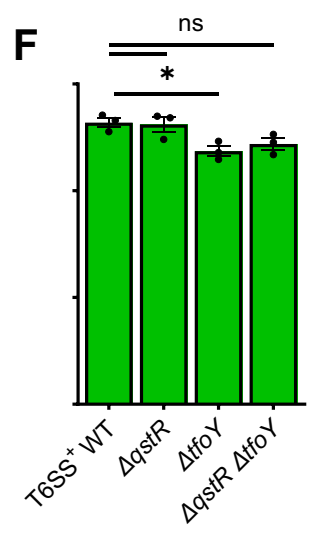

3223-74
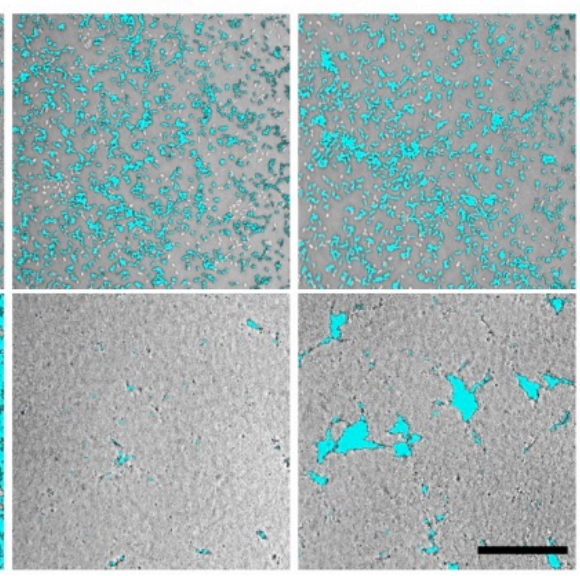
130 region $5^{\prime}$ of vipA derived from the three strains shown. The mean value \pm S.E. of three

131 independent co-cultures $(A-C)$ and monocultures $(D-F)$ are shown from one experiment, with

132 similar results obtained in at least two other independent experiments. A one-way ANOVA

133 with Dunnett post-hoc test was conducted to determine the significance: ns denotes not

134 significant, $* * * * p \leq 0.0001, * * * p \leq 0.001, * * p \leq 0.01, * p \leq 0.05$. (G) E. coli cells expressing

by confocal microscopy. In the images, gfp signal from the $E$. coli is overlaid on top of bright-

light images of the co-culture. Scale bar $=50 \mu \mathrm{m}$.

139 To probe each strain's T6-related regulatory circuitry, we measured canonical behaviors under

142 like several V. cholerae strains, V52 lacks a functional hapR gene that prevents QS and natural transformation $(\underline{35}, \underline{36})$. Nonetheless, V52 encodes a functional tfoY that controls motility (Fig.

$1442 \mathrm{~A}-\mathrm{B})$ (37). Interestingly, the regulatory circuity of V. cholerae 3223-74 is intact, like C6706,

145 confirming that it encodes functional TFs (Fig. 2C), which are nonetheless expendable for T6-

146 mediated killing. Because transposon mutagenesis failed to identify a novel T6 activator (not

147 shown), we suspect regulation may be complex, perhaps involving more than one TF specific 
151 including Vibrios (스).

A

$$
\begin{array}{ll}
\text { No plasmid control } & \Delta \text { hapR (LCD Locked/ } \Delta q s t R) \\
\text { WT } & \Delta l u x O\left(\text { HCD Locked/qst } R^{*}\right)
\end{array}
$$

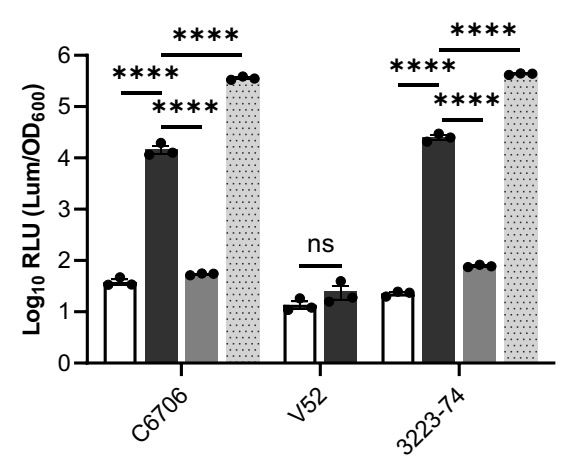

B

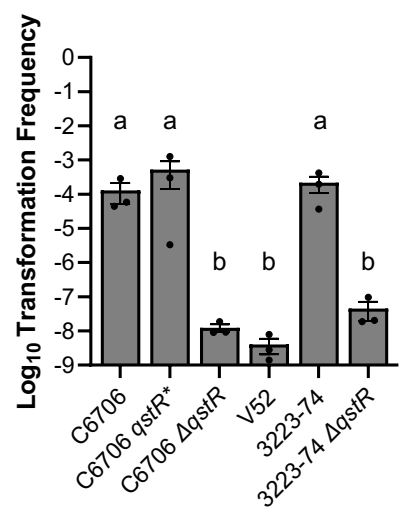

C

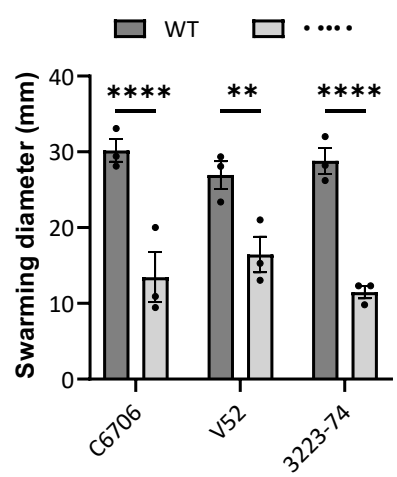

152

153

Figure 2. Vibrio cholerae 3223-74 encodes functional HapR, QstR, and TfoY. (A) V. cholerae

strains were grown in liquid LB with relative luminescence units per $\mathrm{OD}_{600}$ measured at $H C D$

$\left(\mathrm{OD}_{600}=0.6-0.8\right)$. Statistical analyses were conducted with one-way ANOVA with Tukey post$\mathrm{ml}^{-1}$. Statistical analyses were conducted with one-way ANOVA with Tukey post-hoc test. 
163 S.E. from one experiment, with similar results were obtained in at least two other

164 independent experiments. ns: not significant, $* * * * p \leq 0.0001, * * p \leq 0.01$.

A SNP in the T6 intergenic region confers QstR-dependency.

167 Human and environmental isolates of $V$. cholerae we have characterized prior (31) share $\geq 97 \%$

average nucleotide identity with many chromosomal differences (11), but inspection of the

T6 IGRs of C6706, V52 and 3223-74 revealed only 17 SNPs and 3 multinucleotide

171 transcription and killing activity observed. To address this, we replaced the T6 IGR of C6706

175 the robust killing observed by WT V52 and 3223-74 (Fig. 1B-C). Deletion of tfoY in C6706 with

176 V52's IGR increases E. coli survival ( 2-logs), as observed with V52, but does not alter E. coli

177 survival with 3223-74's IGR (Fig. 3B). Chromosomal transcriptional gfp reporters with identical

178 mutations were elevated relative to WT C6706 in each IGR replacement strain (Fig. 3C),

179 consistent with the enhanced killing detected. These results support a hypothesis that a novel

180 CRE lies within the IGR 5' of the T6 locus, despite a lack of any known direct TF-DNA interactions at this locus identified to date. 
bioRxiv preprint doi: https://doi.org/10.1101/2022.01.11.475911; this version posted February 14, 2022. The copyright holder for this preprint (which was not certified by peer review) is the author/funder, who has granted bioRxiv a license to display the preprint in perpetuity. It is made available under aCC-BY-NC-ND 4.0 International license.

A

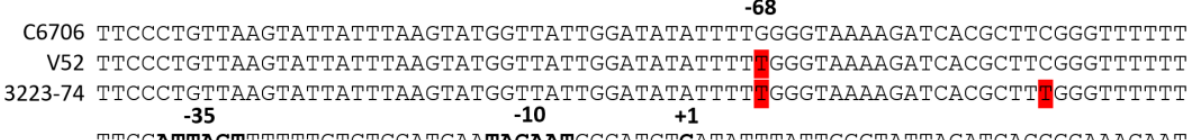
TTCGATTACTTTTTTGTCTCCATGAATAGAATGCCATCTCATATTTATTGGGTATTAGATCACCGCAAACAAT TTCGATTACTTTTTTGTCTCCATGAATAGAATGCCATCTCATATTTATTGGGTATTAGATCACCGCAAACAAT TTCGATTACTTTTTTGTCTCCATGAATAGAATGCCATCTCATATTTATTGGGTATTAGATTGTCGCAAACAAT

ATTTATACCAGATAACTGATACATGGCAGCAAAAAGCTGCTAATGATAAGTTTGCATAATAAGCCCATTTTTC ATTTATACCAGATAACTGATACATGGCAGCAAAAAGCTGCTAATGATAAGTTTGCATAATAAGCCCATTTTTC ATTTAAACAGATAACTGATACATGGIAGCAAAAAGCTGCTAATGATAAGTTTGCATAATAAGCCCATTATTC

ATCAATATATCAAAATACAACAACACTCTGTGACATGGCTTAGTGTGGGATTTATTTTCTCACAGTGTCACGG ATCAATATATCAAAATACAACAACACTCTGTGACATGGCTTAGTGTGGGATTTATTTTCTCACAGTGTCACGG

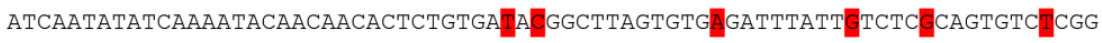

AAGTGATTGACTCT-ATTTCATATTTTGAAATGAGAGCCCTTAGTTATCACTAAGGATAAGTTCAAGATTCTT AAGTGATTGACTCT-ATTTCATATTTTGAAATGAGAGCCCTTAGTTATCACTAAGGATAAGTTCAAGATTCTT AAGTGTTGACTCT TATTTCATATT_TGAAATAGAGCCCTTAGTTATCACTAAGGATAAGTTCAAGATTCTT

GGTTGATTGAATGATTTCAATCAACTGTTTCATTGACAACGTTTGGCATAGGTATTGGAGACGTAATATG GGTTGATTGAATGATTTCAATCAACTGTTTCATTGACAACGTTTGGCATAGGTATTGGAGACGTAATATG GGCTGATTGATTTTTCAATCAGTTGTTCATTGACAACGTTTGGCATAGGTATTGGAGACGTAATATG

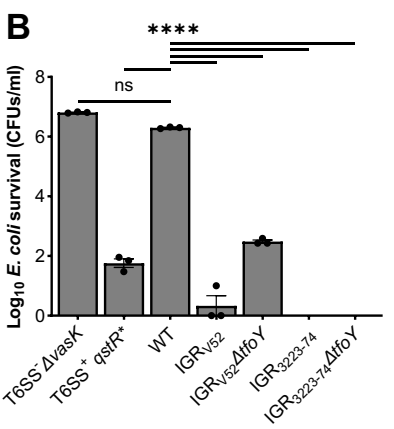

C6706

C

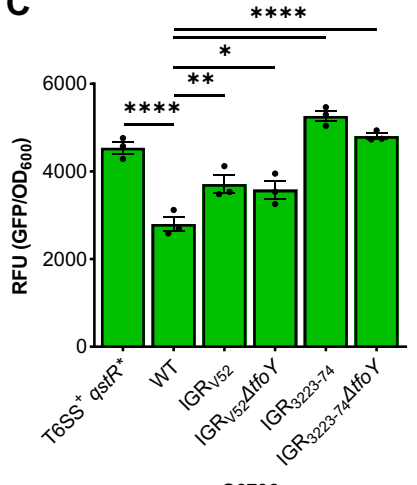

D

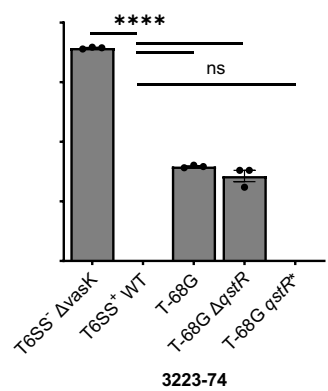

E

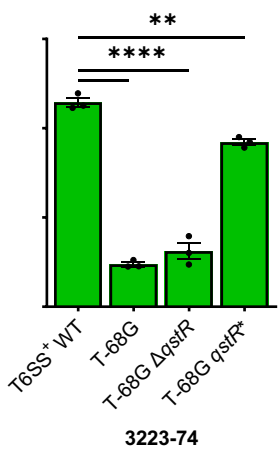

182

183 Figure 3. G-388T mutation abolishes QstR dependence in C6706 and T-388G confers QstR

184 dependence to 3223-74. (A) Alignment of the IGR upstream of vipA was conducted using

185 MUSCLE. SNPs and MNPs are highlighted in red, one gap indicated with a "-", the putative

186 promoter and the transcriptional start site $($ TSS; +1$)$ in bold, and the start codon of vipA in

187 grey. (B) the C6706 5' IGR of vipA was replaced with the IGR from either V52 or 3223-74. (D) 
188 A T-68G mutation in the 5' IGR of vipA was introduced into 3223-74 with different qstR alleles.

189 Competition assays were conducted by co-culturing $V$. cholerae killers and $\mathrm{Cm}^{\mathrm{r}} E$. coli target

190 followed by determination of E. coli survival by counting of colony forming units (CFUs) on LB

191 agar with $\mathrm{Cm}$. (C, E) Shown are fluorescence levels of transcriptional reporters with gfp fused

192 to corresponding IGRs of vipA expressed in either C6706 (C) or 3223-74 (E). The mean value \pm

193 S.E. of three independent co-cultures ( $B$ and $D$ ) and monocultures ( $C$ and $E$ ) are shown from

194 one experiment, with similar results were obtained in at least two other independent

experiments. A one-way ANOVA with Dunnett post-hoc test was conducted to determine the

significance - ns: not significant, $* * * * p \leq 0.0001,{ }^{* *} p \leq 0.01,{ }^{*} p \leq 0.05$.

To begin mapping the T6 IGR region and SNP locations, we experimentally determined the 
reveals a single SNP at -68 , with a guanine (G) in $\mathrm{C} 6706$ at that position and a thymine $(T)$ in

we further tested whether $G$ was necessary for QstR activation by replacing the $T$ with a $G$ at

The SNP at -68 is evolutionarily conserved.

220 To determine whether the SNP at -68 is prevalence in $V$. cholerae, we aligned the T6 IGR

222 (31). Consistent with prior studies $(\underline{11}, \underline{14}, \underline{16}, \underline{18})$, our phylogenetic analysis (Methods) of the

223 T6 IGRs places human strains in a distinct clade, with the exception of two 01 strains isolated nearly a century ago (NCTC8457 and MAK757), and two non-O1 strains (MZO-2 O14 and V52 
activity, with one exception that is chitin-inducible (1496-86) (Fig. 4A, S4). By contrast, the 18

(Fig. 4A, S5). Neither $\mathrm{C}$ nor $\mathrm{A}$ are observed at -68 in any stains tested, although both pyrimidine

similarly (Fig. S3). The focal SNP location is distal from the promoter, but inconsistent with AT-

rich "UP elements" that reside immediately upstream of the promoter at -38 to -59 and

the DNA backbone or DNA-amino acid contacts $(\underline{45}, \underline{46})$. together, our findings reveal that the constitutive T6 killing activity of environmental $V$. 
modest TfoY regulation.

A

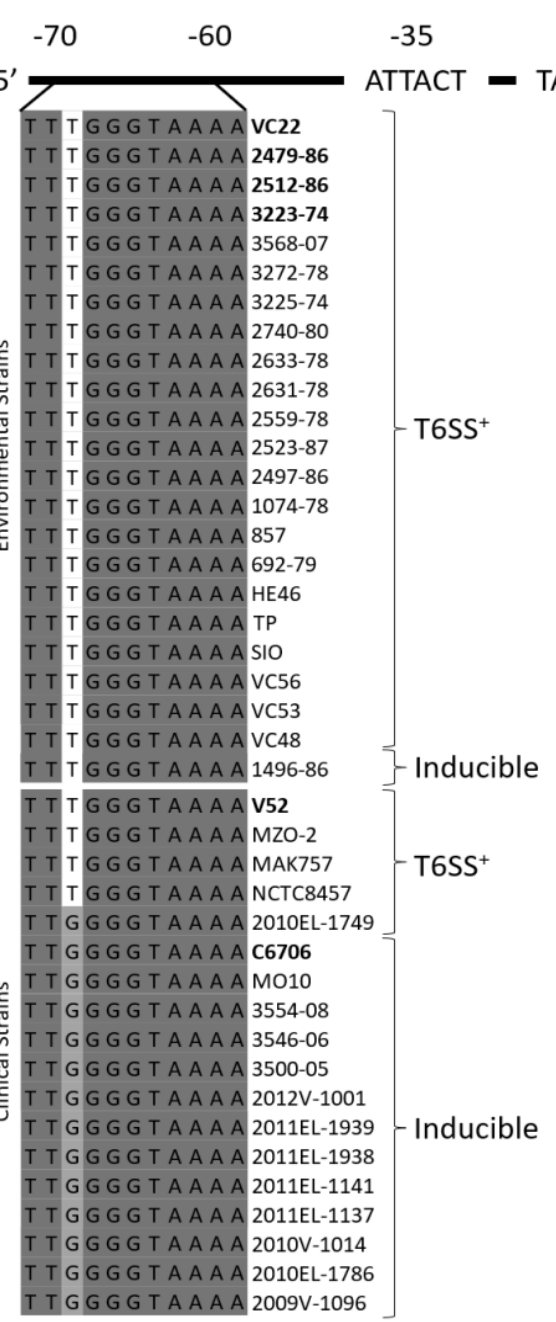

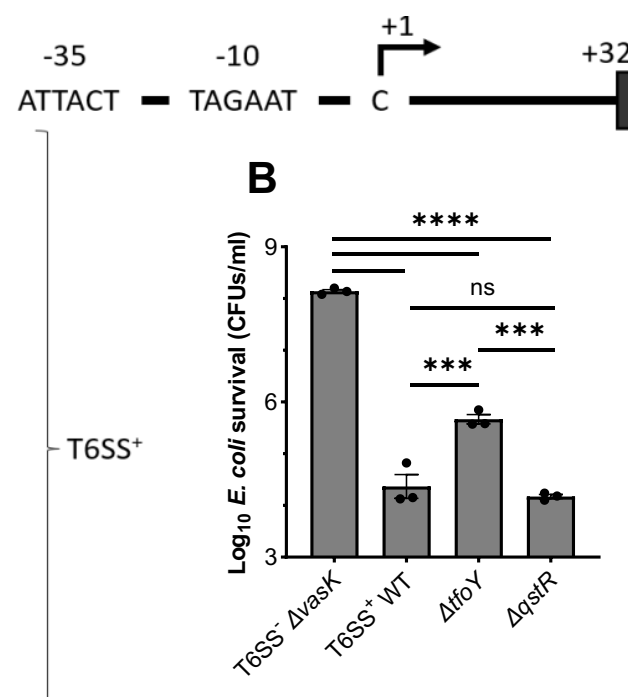

vc22

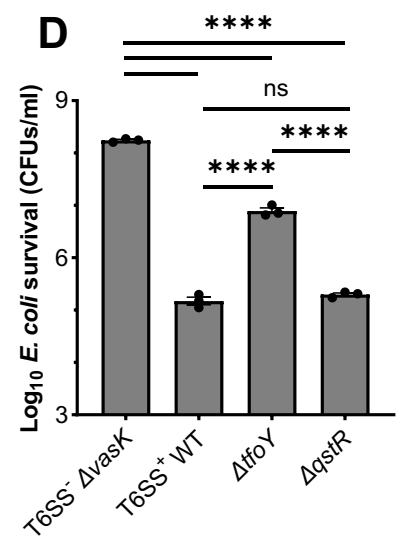

2512-86
321 T6SS Large Cluster
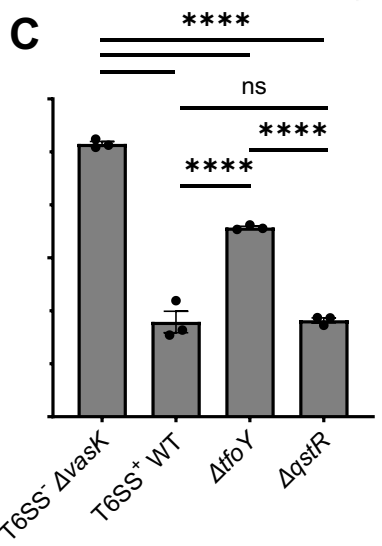

2479-86

$\mathbf{E}$

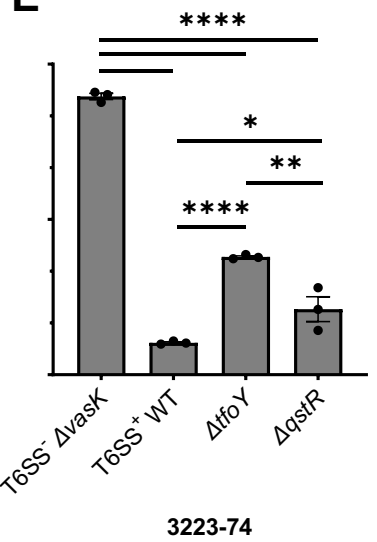

247 Figure 4. Environmental $V$. cholerae isolates encode a $T$ at position - 68 while human, chitin-

induced isolates encode a G. (A) A SNP at position -68 in the IGR of the major T6 cluster

controls killing activity. Conserved nts are in dark grey and the SNP of interest is highlighted in

white/grey. T6 control was categorized as described (1ㅡ). (B-E) Survival of E. coli following

competition assays with WT V. cholerae strains and mutants was determined by CFU counts. 
253 Tukey post-hoc test was conducted to determine the significance - ns: not significant, ****p $\leq$

$0.0001, * * * p \leq 0.001, * * p \leq 0.01, * p \leq 0.05$

Bacterial adaptation to unexploited niches can be the result of horizontal gene transfer events

$(\underline{5})$ as well as mutations in protein coding and promoter regions $(\underline{47}, \underline{48})$. Here we describe an

intergenic non-coding SNP that coordinates adaptation by altering T6 control between two

states - one that in inducible and the other that displays constitutive activity. While the first

Type VI Secretion System was first described in V. cholerae in 2006, the knowledge of its

267 (49), with varying degrees of TfoY contribution, which may act directly or indirectly at the

270 (inducible T6) are favored. In fact, T6-deficient human isolates (e.g. O395) have been reported

271 to have less competitive fitness in human intestinal colonization and infection (19, $\underline{50})$. 
272 Although low level, basal expression of T6 contributes to pathogenesis of C6706 (51),

273 overexpression of T6SS may be deleterious in vivo. Indeed, we have reported prior that $V$.

274 cholerae with constitutive T6SS induces violent peristaltic contractions in a fish host (52),

275 which may disrupt the interaction between $V$. cholerae and the gut microflora.

277 There remains a pressing public health need to understand the emergence of pathogens from

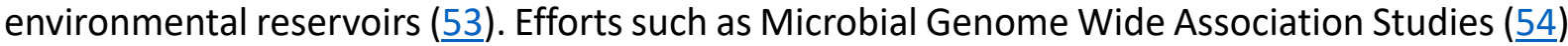
to identify genetic variants in genomes that are associated with phenotypes like virulence and antibiotic sensitivity, will be bolstered by knowledge of the ecological and evolutionary processes that promote pathogen-host association. Defining the plasticity of the regulatory circuity controlling the T6 weapon will provide insights into the role of polymorphisms in the evolution of this and other pathogens.

\section{Materials and Methods}

287 All V. cholerae and E. coli (Table S1) strains were grown aerobically at $37{ }^{\circ} \mathrm{C}$ overnight in Lysogeny Broth (LB) with constant shaking or statically on LB agar. Ampicillin $(100 \mu \mathrm{g} / \mathrm{ml})$,

289 kanamycin $(50 \mu \mathrm{g} / \mathrm{ml})$, chloramphenicol $(10 \mu \mathrm{g} / \mathrm{ml})$, spectinomycin $(100 \mu \mathrm{g} / \mathrm{ml})$, streptomycin 
appropriate.

293 Plasmids (Table S2) used were constructed with DNA restriction nucleases (Promega - WI,

294 USA), Gibson Assembly mix (New England Biolabs - MA, USA), and PCR amplification (Qiagen

295 - Hilden, Germany) by PCR with Q5 polymerase (New England Biolabs - MA, USA), and primers

296 (Table S3) generated by Eton Bioscience Inc (NC, USA) or Eurofins Genomics (KY, USA). All

reagents were used according to the manufacturer's instructions. Plasmids were confirmed

by PCR and Sanger sequencing by Eton Bioscience Inc (NC, USA).

\section{V. cholerae mutant construction}

301 All genetically engineered strains of $V$. cholerae were constructed with established allelic 
310 to dry. Cells were imaged before and after a $3 \mathrm{~h}$ incubation at $37^{\circ} \mathrm{C}$ and $96-100 \%$ humidity

311 using an Eclipse Ti-E Nikon (NY, USA) inverted microscope with a Perfect Focus System and

312 camera previously described (11). The images were processed with ImageJ (34).

$314 \quad$ Motility assay

315 Overnight cultures of $V$. cholerae were diluted to $\mathrm{OD}_{600}=0.1$, and $1 \mu \mathrm{L}$ inoculated onto pre-

316 dried LB plates with $0.3 \%$ agar. Cells were incubated at $37^{\circ} \mathrm{C}$ statically overnight, with motility

317 determined by measuring the swarming diameter.

Transformation assay

320 Chitin-induced transformation frequency was measured as described with defined artificial

sea water $\left(450 \mathrm{mM} \mathrm{NaCl}, 10 \mathrm{mM} \mathrm{KCl}, 9 \mathrm{mM} \mathrm{CaCl}, 30 \mathrm{mM} \mathrm{MgCl} 2 \cdot 6 \mathrm{H}_{2} \mathrm{O}\right.$, and $16 \mathrm{mM}$

327 Overnight cultures of the bacterial strains were diluted to $\mathrm{OD}_{600}=0.001$ in liquid $\mathrm{LB}$ in 
bioRxiv preprint doi: https://doi.org/10.1101/2022.01.11.475911; this version posted February $14,2022$. The copyright holder for this

preprint (which was not certified by peer review) is the author/funder, who has granted bioRxiv a license to display the preprint in perpetuity. It is made available under aCC-BY-NC-ND 4.0 International license.

measured each h with a BioTek (VT, USA) Synergy H1 microplate reader to calculate Relative

Luminescence Units (RLU) as Luminescence/ $\mathrm{OD}_{600}$. Data were collected when $\mathrm{OD}_{600}=0.6-0.8$.

331 LB medium was used as the blank for the $\mathrm{OD}_{600}$ and luminescence.

Overnight cultures of $V$. cholerae or $E$. coli were diluted $1: 100$ and incubated at $37^{\circ} \mathrm{C}$ for $3 \mathrm{~h}$.

To enhance the translation of $g f p$, the sequence of the native RBS (12 nt sequence) was

added to maintain the plasmid-borne versions of reporters that were cloned into plasmid

pSLS3. $300 \mu \mathrm{L}$ aliquots were transferred to black microtiter plates to read the $\mathrm{OD}_{600}$ and GFP

RFU was calculated by blanked GFP fluorescence / blanked $\mathrm{OD}_{600}$.

345 Overnight cultures of $V$. cholerae or $E$. coli were back-diluted $1: 100$ and incubated at $37{ }^{\circ} \mathrm{C}$ for

$3463 \mathrm{~h}$. V. cholerae strains and the $\mathrm{Cm}^{r}$ E. coli target were normalized to $\mathrm{OD}_{600}=1$ and then mixed

347 at a ratio of either 10:1 or 1:5. A $50 \mu \mathrm{L}$ mixed culture was spotted onto LB agar and dried. After 
a $3 \mathrm{~h}$ incubation at $37^{\circ} \mathrm{C}$, cells were resuspended in $5 \mathrm{ml}$ of $\mathrm{LB}$, and serial dilutions were

conducted. Finally, the resuspension was inoculated on a LB agar containing $\mathrm{Cm}$ to select for

the surviving E. coli, which was incubated overnight at $37{ }^{\circ} \mathrm{C}$ and the $E$. coli colonies were

counted and shown as CFU $\mathrm{mL}^{-1}$.

352

RNA extraction and determination of the +1 of transcription by $5^{\prime}$-RACE

Overnight cultures of $V$. cholerae were back-diluted $1: 100$ and incubated at $37^{\circ} \mathrm{C}$ for $3 \mathrm{~h}$ before

lysing. Three independent cultures of T6-active V. cholerae C6706 qst $R^{*}$ and 3223-74 WT were

harvested by centrifugation at room temperature. RNA isolation, genomic DNA removal, and

RNA clean-up were performed as previously described (57). Genomic DNA contamination was

confirmed by conducting PCR with primer pair specific for $16 \mathrm{~S}$ rRNA loci ( $r r s A)$ as previously

described (Table S3) (료). RNA purity was confirmed by NanoDrop ( $260 / 280 \approx 2.0$ ).

5'-RACE (Invitrogen ${ }^{\mathrm{TM}}-\mathrm{MA}$, USA) was conducted according to the manufacturer's protocol

with slight modifications. Specifically, SuperScript ${ }^{\mathrm{TM}}$ IV reverse transcriptase (Invitrogen ${ }^{\mathrm{TM}}$ cluster (Table S3). PCR products were purified with QIAquick PCR purification kit (Qiagen - 
primer (Table S3).

Genomic and phylogenetic analysis

371 Genome sequences of $V$. cholerae strains were collected from NCBI Genome database (Table 
bioRxiv preprint doi: https://doi.org/10.1101/2022.01.11.475911; this version posted February $14,2022$. The copyright holder for this

preprint (which was not certified by peer review) is the author/funder, who has granted bioRxiv a license to display the preprint in perpetuity. It is made available under aCC-BY-NC-ND 4.0 International license.

385 We would like to thank Dr. Jyl S. Matson for assistance with RNA isolation and Dr. Marvin

386 Whiteley and current and past members of the Hammer Lab for critiques and discussion,

387 specifically, Dr. Samit Watve and Rakin Choudhury for bioinformatic advice and assistance.

388

389 Competing interests

390 The authors have no competing interests. 


\section{References}

392 1. Wray GA. The evolutionary significance of cis-regulatory mutations. Nature reviews

393 Genetics. 2007;8(3):206-16. Epub 2007/02/17. doi: 10.1038/nrg2063. PubMed PMID:

17304246.

395

2. Stern DL, Orgogozo V. THE LOCI OF EVOLUTION: HOW PREDICTABLE IS GENETIC

EVOLUTION? Evolution. 2008;62(9):2155-77. doi: https://doi.org/10.1111/j.1558-

397

5646.2008.00450.x.

398

3. Wittkopp PJ, Kalay G. Cis-regulatory elements: molecular mechanisms and evolutionary

399 processes underlying divergence. Nature reviews Genetics. 2011;13(1):59-69. Epub 2011/12/07. doi: 10.1038/nrg3095. PubMed PMID: 22143240.

401

4. Norsworthy AN, Visick KL. Signaling between two interacting sensor kinases promotes

402 biofilms and colonization by a bacterial symbiont. Mol Microbiol. 2015;96(2):233-48. Epub 2015/01/15. doi: 10.1111/mmi.12932. PubMed PMID: 25586643; PMCID: PMC4465548.

404

5. Mandel MJ, Wollenberg MS, Stabb EV, Visick KL, Ruby EG. A single regulatory gene is 405 sufficient to alter bacterial host range. Nature. 2009;458(7235):215-8. Epub 2009/02/03. doi: 10.1038/nature07660. PubMed PMID: 19182778; PMCID: PMC2713604.

407 6. Perez JC, Groisman EA. Evolution of transcriptional regulatory circuits in bacteria. Cell. 408 2009;138(2):233-44. Epub 2009/07/28. doi: 10.1016/j.cell.2009.07.002. PubMed PMID: 
410 7. Dziejman M, Balon E, Boyd D, Fraser CM, Heidelberg JF, Mekalanos JJ. Comparative

411 genomic analysis of Vibrio cholerae: genes that correlate with cholera endemic and pandemic

412 disease. Proceedings of the National Academy of Sciences of the United States of America.

413 2002;99(3):1556-61. Epub 2002/01/31. doi: 10.1073/pnas.042667999. PubMed PMID:

414 11818571; PMCID: PMC122229.

415 8. Faruque SM, Albert MJ, Mekalanos JJ. Epidemiology, Genetics, and Ecology of

416 Toxigenic $<$ i>Vibrio cholerae $<$ i $>$. Microbiology and Molecular Biology Reviews.

417 1998;62(4):1301-14. doi: doi:10.1128/MMBR.62.4.1301-1314.1998.

418 9. Karaolis DKR, Johnson JA, Bailey CC, Boedeker EC, Kaper JB, Reeves PR. A <em>Vibrio

419 cholerae</em> pathogenicity island associated with epidemic and pandemic strains.

420 Proceedings of the National Academy of Sciences. 1998;95(6):3134-9. doi:

$421 \quad 10.1073 /$ pnas.95.6.3134.

422 10. Pruzzo C, Vezzulli L, Colwell RR. Global impact of Vibrio cholerae interactions with chitin.

423 Environ Microbiol. 2008;10(6):1400-10. Epub 2008/03/04. doi: 10.1111/j.1462-

424 2920.2007.01559.x. PubMed PMID: 18312392.

425 11. Crisan CV, Chande AT, Williams K, Raghuram V, Rishishwar L, Steinbach G, Watve SS,

426 Yunker P, Jordan IK, Hammer BK. Analysis of Vibrio cholerae genomes identifies new type VI

427 secretion system gene clusters. Genome Biol. 2019;20(1):163. Epub 2019/08/14. doi: 
12. MacIntyre DL, Miyata ST, Kitaoka M, Pukatzki S. The Vibrio cholerae type VI secretion

system displays antimicrobial properties. Proceedings of the National Academy of Sciences of

431 the United States of America. 2010;107(45):19520-4. Epub 2010/10/27. doi:

13. Gallegos-Monterrosa R, Coulthurst SJ. The ecological impact of a bacterial weapon:

Microbiology. 2021;12(979). doi: 10.3389/fmicb.2021.671092.

444 immunity gene arrays in Vibrio cholerae. Scientific Reports. 2017;7(1):45133. doi: 
10.15698/mic2021.03.744. PubMed PMID: 33681340; PMCID: PMC7919388.

449 18. Unterweger D, Miyata ST, Bachmann V, Brooks TM, Mullins T, Kostiuk B, Provenzano D,

450 Pukatzki S. The Vibrio cholerae type VI secretion system employs diverse effector modules for

451 intraspecific competition. Nature Communications. 2014;5(1):3549. doi:

$45210.1038 /$ ncomms4549.

453 19. Kostiuk B, Santoriello FJ, Diaz-Satizabal L, Bisaro F, Lee K-J, Dhody AN, Provenzano D,

454 Unterweger D, Pukatzki S. Type VI secretion system mutations reduced competitive fitness of

classical Vibrio cholerae biotype. Nature Communications. 2021;12(1):6457. doi:

20. Crisan CV, Chandrashekar H, Everly C, Steinbach G, Hill SE, Yunker PJ, Lieberman RR,

doi:

doi: https://doi.org/10.1111/1462-2920.15224. 
PMC5365375.

PMC7371385. induction to render Vibrio cholerae naturally transformable. Nucleic Acids Res. 
PMCID: PMC3616704.

28. Meibom KL, Blokesch M, Dolganov NA, Wu CY, Schoolnik GK. Chitin induces natural

competence in Vibrio cholerae. Science. 2005;310(5755):1824-7. Epub 2005/12/17. doi:

29. Watve SS, Thomas J, Hammer BK. CytR Is a Global Positive Regulator of Competence,

PMC4581735.

494

30. Tsou AM, Cai T, Liu Z, Zhu J, Kulkarni RV. Regulatory targets of quorum sensing in Vibrio

56. Epub 2009/03/12. doi: 10.1093/nar/gkp121. PubMed PMID: 19276207; PMCID:

PMC2677876.

498

31. Bernardy EE, Turnsek MA, Wilson SK, Tarr CL, Hammer BK, Liu S-J. Diversity of Clinical and

Environmental Isolates of Vibrio cholerae in Natural Transformation and Contact-Dependent

Microbiology. 2016;82(9):2833-42. doi: doi:10.1128/AEM.00351-16.

503 cholerae HA/protease gene hap, and its identification as a functional homologue of the Vibrio

504 harveyi luxR gene. Molecular Microbiology. 1997;26(5):1023-34. doi: 
507 Regulates TfoY in Vibrio cholerae To Control Motility by both Transcriptional and

508 Posttranscriptional Mechanisms. J Bacteriol. 2018;200(7). Epub 2018/01/10. doi:

10.1128/JB.00578-17. PubMed PMID: 29311281; PMCID: PMC5847662.

510

34. Schneider CA, Rasband WS, Eliceiri KW. NIH Image to ImageJ: 25 years of image analysis.

Nat Methods. 2012;9(7):671-5. Epub 2012/08/30. doi: 10.1038/nmeth.2089. PubMed PMID:

35. Zheng J, Shin OS, Cameron DE, Mekalanos JJ. Quorum sensing and a global regulator TsrA

control expression of type VI secretion and virulence in $<$ em $>$ Vibrio cholerae $</$ em $>$.

515 Proceedings of the National Academy of Sciences. 2010;107(49):21128-33. doi:

10.1073/pnas.1014998107.

517 36. Joelsson A, Liu Z, Zhu J. Genetic and phenotypic diversity of quorum-sensing systems in

518 clinical and environmental isolates of Vibrio cholerae. Infect Immun. 2006;74(2):1141-7. Epub

PMC1360356. 
524 38. Holowka J, Zakrzewska-Czerwinska J. Nucleoid Associated Proteins: The Small Organizers

525 That Help to Cope With Stress. Front Microbiol. 2020;11:590. Epub 2020/05/07. doi:

526 10.3389/fmicb.2020.00590. PubMed PMID: 32373086; PMCID: PMC7177045.

39. Ayala JC, Silva AJ, Benitez JA. H-NS: an overarching regulator of the Vibrio cholerae life

cycle. Res Microbiol. 2017;168(1):16-25. Epub 2016/08/06. doi:

40. Chaparian RR, Olney SG, Hustmyer CM, Rowe-Magnus DA, van Kessel JC. Integration host

PMID: 27191515.

41. Papenfort K, Forstner KU, Cong JP, Sharma CM, Bassler BL. Differential RNA-seq of Vibrio

PMC4343088.

539 42. Shao Y, Bassler BL. Quorum regulatory small RNAs repress type VI secretion in Vibrio

540 cholerae. Mol Microbiol. 2014;92(5):921-30. Epub 2014/04/05. doi: 10.1111/mmi.12599.

541 PubMed PMID: 24698180; PMCID: PMC4038675.

542 43. Drebes Dörr NC, Proutière A, Jaskólska M, Stutzmann S, Bader L, Blokesch M. A single 
543 nucleotide polymorphism determines constitutive versus inducible type VI secretion in

doi:

44. Gourse RL, Ross W, Gaal T. UPs and downs in bacterial transcription initiation: the role of

547 the alpha subunit of RNA polymerase in promoter recognition. Mol Microbiol.

PMID: 10972792. doi: $10.1186 / s 12864-017-3785-4$. code: how transcription factors read the genome. Trends in Biochemical Sciences.

PLoS Genet. 2019;15(6):e1008233. Epub 2019/06/25. doi: 10.1371/journal.pgen.1008233. 
562 bacteria by rewiring a $<$ em $>$ cis $</$ em $>$-regulatory input function. Proceedings of the National

563 Academy of Sciences. 2009;106(10):3982-7. doi: 10.1073/pnas.0811669106.

564 49. Unterweger D, Kitaoka M, Miyata ST, Bachmann V, Brooks TM, Moloney J, Sosa O, Silva D,

565 Duran-Gonzalez J, Provenzano D, Pukatzki S. Constitutive type VI secretion system expression

566 gives Vibrio cholerae intra- and interspecific competitive advantages. PLoS One.

567 2012;7(10):e48320. Epub 2012/10/31. doi: 10.1371/journal.pone.0048320. PubMed PMID:

23110230; PMCID: PMC3482179.

569

50. Fu Y, Waldor MK, Mekalanos JJ. Tn-Seq analysis of Vibrio cholerae intestinal colonization

reveals a role for T6SS-mediated antibacterial activity in the host. Cell Host Microbe.

571 2013;14(6):652-63. Epub 2013/12/18. doi: 10.1016/j.chom.2013.11.001. PubMed PMID:

573 51. Zhao W, Caro F, Robins W, Mekalanos JJ. Antagonism toward the intestinal microbiota

574 and its effect on Vibrio cholerae virulence. Science. 2018;359(6372):210-3. Epub 2018/01/13.

575 doi: 10.1126/science.aap8775. PubMed PMID: 29326272; PMCID: PMC8010019.

576 52. Logan SL, Thomas J, Yan J, Baker RP, Shields DS, Xavier JB, Hammer BK, Parthasarathy R.

577 The <em $>$ Vibrio cholerae</em> type VI secretion system can modulate host intestinal

578 mechanics to displace gut bacterial symbionts. Proceedings of the National Academy of

579 Sciences. 2018;115(16):E3779-E87. doi: 10.1073/pnas.1720133115. 
581 A missing experimental paradigm. Elife. 2021;10. Epub 2021/09/22. doi: 10.7554/eLife.68874.

and Analytical Pitfalls. Front Microbiol. 2019;10:3119. Epub 2020/02/23. doi:

55. Skorupski K, Taylor RK. Positive selection vectors for allelic exchange. Gene. 1996;169(1):47-52. Epub 1996/02/22. doi: 10.1016/0378-1119(95)00793-8. PubMed PMID:

8635748.

56. Watve SS, Bernardy EE, Hammer BK. Vibrio cholerae: Measuring Natural Transformation

591 Frequency. Curr Protoc Microbiol. 2014;35:6A 4 1-12. Epub 2014/11/05. doi:

Biol. 2018;1839:29-38. Epub 2018/07/27. doi: 10.1007/978-1-4939-8685-9_3. PubMed PMID: 
architecture and applications. BMC Bioinformatics. 2009;10:421. Epub 2009/12/17. doi:

61. Edgar RC. MUSCLE: multiple sequence alignment with high accuracy and high throughput.

612 Potter SC, Finn RD, Lopez R. The EMBL-EBI search and sequence analysis tools APIs in 2019.

613 Nucleic Acids Res. 2019;47(W1):W636-W41. Epub 2019/04/13. doi: 10.1093/nar/gkz268.

614 PubMed PMID: 30976793; PMCID: PMC6602479.

615 63. Felsenstein J. Evolutionary trees from DNA sequences: a maximum likelihood approach.

616 J Mol Evol. 1981;17(6):368-76. Epub 1981/01/01. doi: 10.1007/BF01734359. PubMed PMID:

6177288891.

618 64. Tamura K, Stecher G, Kumar S. MEGA11: Molecular Evolutionary Genetics Analysis 
bioRxiv preprint doi: https://doi.org/10.1101/2022.01.11.475911; this version posted February 14, 2022. The copyright holder for this preprint (which was not certified by peer review) is the author/funder, who has granted bioRxiv a license to display the preprint in perpetuity. It is made available under aCC-BY-NC-ND 4.0 International license.

619 Version 11. Mol Biol Evol. 2021;38(7):3022-7. Epub 2021/04/24. doi:

620 10.1093/molbev/msab120. PubMed PMID: 33892491; PMCID: PMC8233496.

621 